\title{
Article
}

\section{Optimization of bleaching power by sulfuric acid activation of bentonite}

\author{
Hale Bayram ${ }^{1}$, Gokce Ustunisik'2,3, Müşerref Önal ${ }^{4 \star}$ (D) and Yüksel Sarıkaya4 \\ ${ }^{1}$ Atatürk Faculty on Education, Marmara University Göztepe, i̇stanbul, Turkey; ${ }^{2}$ Department of Geology and Geological Engineering, South Dakota School of Mines \\ and Technology, Rapid City, SD 57701-3995, USA; ${ }^{3}$ Department of Earth and Planetary Science, American Museum of Natural History, New York, NY 10024-5192, USA \\ and ${ }^{4}$ Department of Chemistry, Faculty of Science, Ankara University, 06100 Tandoğan, Ankara, Turkey
}

\begin{abstract}
Acid activation was carried out by heating muds prepared from Ca-rich bentonite (CaB), sulfuric acid $\left(\mathrm{H}_{2} \mathrm{SO}_{4}\right)$ and distilled water, yielding various bleaching earths (BEs). The roles of each of the process variables, namely mass fraction of $\mathrm{H}_{2} \mathrm{SO}_{4}(x)$ in the dried $\mathrm{CaB}$ and pure $\mathrm{H}_{2} \mathrm{SO}_{4}$ mixture, heating temperature $(T)$ and contact time $(t)$, in the activation were tested. The raw $\mathrm{CaB}$ and each $\mathrm{BE}$ were examined with X-ray diffraction, chemical analyses, $\mathrm{N}_{2}$ adsorption/desorption, $\mathrm{pH}$-metry and tintometry. The BE contents in both the aqueous and oily suspensions were set to $2 \%$ by mass in order to measure the $\mathrm{pH}$ value and the bleaching power, respectively. The optimum conditions for the activation to obtain a BE having the same bleaching power (0.60) as Tonsil ${ }^{\circledR}$ Optimum Bleaching Earth for soybean oil were determined as $x=0.35, T=100^{\circ} \mathrm{C}$ and $t=2 \mathrm{~h}$. The bleaching power increased only marginally upon increasing the activation time from $2 \mathrm{~h}$ up to $10 \mathrm{~h}$ at a given $x$ and $T$. After $10 \mathrm{~h}$, significant changes did not take place in the bleaching power of the BE. The mass fraction of total structural metal oxide $(y), \mathrm{pH}$ value, specific pore volume $(V)$, specific surface area $(S)$ and mean internal diameter $(D)$ of the mesopores for the optimized $\mathrm{BE}$ are $y=0.10, \mathrm{pH}=3.0, V=0.31 \mathrm{~cm}^{3} \mathrm{~g}^{-1}, S=225 \mathrm{~m}^{2} \mathrm{~g}^{-1}$ and $D=7 \mathrm{~nm}$. The $\mathrm{pH}$ and $D$ values were more important for bleaching the alkaline refined soybean oil compared to the other parameters tested.
\end{abstract}

Keywords: acid activation, bentonite, bleaching, porosity, soybean oil

(Received 16 March 2021; revised 9 September 2021; Accepted Manuscript online: 22 September 2021; Associate Editor: Stephan Kaufhold)

Crude vegetable edible oils are produced by compression or solvent extraction of soybean, cottonseed, sesame, coconut, olive, safflower, sunflower, corn, rapeseed, mustard seed, peanut and palm oils. They are processed by both chemical and physical refining techniques (Mounts, 1981; Zschau, 1999). The conventional chemical techniques consist of acid degumming, alkali refining, bleaching, deodorization and winterization stages (Rich, 1964; Almeida et al., 2019; Hew et al., 2020).

In addition to organic pigments such as chlorophyll, carotenoids and related compounds, other impurities such as soaps, sulfur, phosphates, trace metal cations and their decomposition products are removed from the alkali-refined oils by adsorption and ion exchange through bleaching (Falaras et al., 1999; Taxiarchou \& Douni, 2014; Saneei et al., 2015; Awad et al., 2019). Previous studies on the kinetics of the bleaching of vegetable oils (Brimberg, 1982) showed that the catalytic effect of the bleaching earth (BE) causes lengthy chemisorbed $\beta$-carotene molecules to immediately decompose to form shorter molecules. As this decomposition causes a colour change from white to greyblue, the bleaching power (BP) is more conveniently measured by the adsorption of chlorophyll rather than $\beta$-carotene. In addition to the carbonaceous materials (Omar et al., 2003), a variety of raw

${ }^{\star}$ E-mail: onal@science.ankara.edu.tr

Cite this article: Bayram H, Ustunisik G, Önal M, Sarıkaya Y (2021). Optimization of bleaching power by sulfuric acid activation of bentonite. Clay Minerals 56, 148-155. https://doi.org/10.1180/clm.2021.28 and modified clays such as attapulgite (Huang et al., 2007), sepiolite (Tian et al., 2014; Laatikainen et al., 2015) and bentonite (Komadel, 2003; Noyan et al., 2007) have also been used for the bleaching of various edible and mineral oils. In general, raw and acid-activated clays are called 'Fuller's earths' and 'bleaching earths', respectively (Zschau, 1985; Sohling et al., 2009; Emmerich et al., 2010; Liang et al., 2020). Such adsorbents are also used in other processes such as the clarification of wine, beer and fruit juice, as well as in the removal of contaminants from wastewater (Bombos et al., 2014; Silva et al., 2014; Zhu et al., 2016; Uddin, 2017).

Bleaching earths are produced through the acid activation of calcium bentonites (Önal \& Sarıkaya, 2007; Komadel, 2016) after treatment with hydrochloric acid or sulfuric acid $\left(\mathrm{H}_{2} \mathrm{SO}_{4}\right)$. Smectites such as montmorillonite, saponite, hectorite, nontronite and beidellite are the major clay minerals of bentonites (Bergaya et al., 2006), which also include other clay and non-clay minerals as impurities (Moore \& Reynolds, 1997, Sohling et al., 2009; Steudel et al., 2013). The mineralogical and physicochemical characteristics of bentonites and other clays vary significantly depending on the acid as well as alkali treatments (Pentrák et al., 2009; Mache et al., 2015).

Although Rich (1964) stated that the oil quality is the most important parameter impacting BP (compared to the clay type and the bleaching method), the physicochemical properties of clay minerals and their effect on BP have been investigated systematically. The role of changing the physicochemical properties

(C) The Author(s), 2021. Published by Cambridge University Press on behalf of The Mineralogical Society of Great Britain and Ireland. This is an Open Access article, distributed under the terms of the Creative Commons Attribution licence (https://creativecommons.org/licenses/by/4.0/), which permits unrestricted re-use, distribution, and reproduction in any medium, provided the original work is properly cited. 
Table 1. The amounts of $\mathrm{H}_{2} \mathrm{SO}_{4}$ and water in the mud samples prepared using $20 \mathrm{~g}$ of bentonite. The effect of activation temperature was tested at $2 \mathrm{~h}$ and $x\left(\mathrm{H}_{2} \mathrm{SO}_{4}\right)=0.35$ based on the optimum BP attained at various total structural metal oxides $y\left(\mathrm{R}_{x} \mathrm{O}_{y}\right)$, as shown in Fig. 3. An activation temperature of $100^{\circ} \mathrm{C}$, $x\left(\mathrm{H}_{2} \mathrm{SO}_{4}\right)=0.35$ and $y\left(\mathrm{R}_{x} \mathrm{O}_{y}\right)=0.10$ were selected to test the various activation times according to the largest BP value observed in Fig. 4.

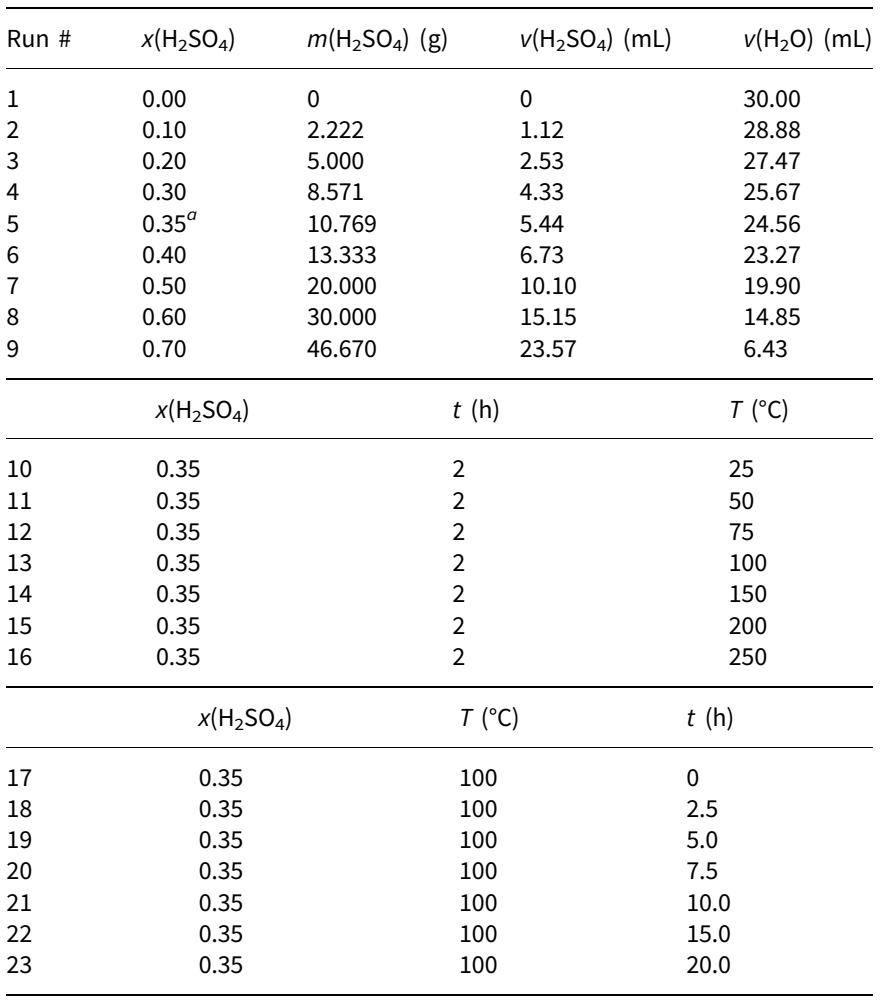

${ }^{a}$ This specific $x\left(\mathrm{H}_{2} \mathrm{SO}_{4}\right)$ concentration of 0.35 is selected for the next set of time and temperature series experiments based on highest BP observed in Fig. 2 (black dashed line).

of acid-activated montmorillonite on its bleaching efficiency was studied by Falaras et al. (1999), who showed that bleaching efficiency increases with increasing acidity and specific surface area, where medium activation of montmorillonite is the most efficient way to bleach cottonseed oil, producing the best colour index and lowest peroxide value. Falaras et al. (2000) investigated the physical and chemical properties of pillared materials to understand their effects on bleaching efficiency in the processing of cottonseed oil and concluded that the Al-pillared acid-activated material was comparable to Tonsil $^{\circledR}$ Optimum Bleaching Earth (TOBE). Because every clay sample has slightly different mineralogical and geochemical properties, bleaching powder that is produced through acid activation of the clay may result in variation in adsorption properties such as porosity, specific surface area and pore-size distribution.

$\mathrm{Na}$-rich bentonites $(\mathrm{NaBs})$ and $\mathrm{Ca}$-rich bentonites $(\mathrm{CaBs})$ are clays that contain Na-smectite (Na-Sme) or Ca-smectite (Ca-Sme) as major clay minerals (Mache et al., 2015; Koutsopoulou et al., 2016). Pure smectites are rarely found in the Earth's crust, and they are separated from the bentonites. Bentonites can be activated by various treatments. Acid activation affects the $\mathrm{pH}$ and porosity of the bentonites. The void volumes in the solid particles with internal widths of $<2,2-50$ and $>50 \quad \mathrm{~nm}$ are called micropores, mesopores and macropores, respectively (Rouquerol et al., 2014). The BP of an acid-activated powder for a vegetable oil changes depending on pore volume $(V)$, specific surface area $(S)$ and pore width $(D)$ (Önal \& Sarıkaya, 2012).
Previous studies revealed that the performance of BEs depends on the mineralogical and chemical composition of the raw bentonite selected, the type and amount of the inorganic acid, the temperature and contact time for the activation process, as well as the type and composition of the impurities in the vegetable oil (Christidis et al., 1997; Falaras et al., 1999, 2000, Özgüven et al., 2020). However, these studies did not investigate systematically the individual and combined effects of activation parameters (mass fraction of inorganic acid, temperature or contact time). The goal of this study was to evaluate systematically the optimum conditions for the $\mathrm{H}_{2} \mathrm{SO}_{4}$ activation of a Turkish bentonite to produce a powder with the maximum BP for soybean oil by analysing the individual and combined effects of activation variables, including mass fraction of $\mathrm{H}_{2} \mathrm{SO}_{4}(x)$ per dried $\mathrm{CaB}$ and pure $\mathrm{H}_{2} \mathrm{SO}_{4}$ mixture, heating temperature $(T)$ and contact time $(t)$, as well as their relationship with $S, V$ and $D$.

\section{Materials and methods}

\section{Materials}

A white $\mathrm{CaB}$, obtained from the Çamlıdere, Ankara (Turkey) deposit, was used as the starting material after grinding to pass through a $0.074 \mathrm{~mm}$ (200 mesh) sieve and drying at $105^{\circ} \mathrm{C}$ for $4 \mathrm{~h}$. The bulk chemical composition of the dried $\mathrm{CaB}$ (mass \%) is $\mathrm{SiO}_{2}: 72.1, \mathrm{Al}_{2} \mathrm{O}_{3}: 14.8, \mathrm{Fe}_{2} \mathrm{O}_{3}: 0.8, \mathrm{MgO}: 1.6, \mathrm{CaO}: 2.2$, $\mathrm{Na}_{2} \mathrm{O}: 0.4, \mathrm{~K}_{2} \mathrm{O}: 1.1, \mathrm{TiO}_{2}: 0.1$ and loss on ignition (LOI): 7.0. The cation-exchange capacity (CEC) estimated based on the methylene blue method was 0.78 eq. $\mathrm{kg}^{-1}$ (Kipling \& Wilson, 1960; Hang \& Brindley, 1970; Rytwo et al., 1991; Kahr \& Madson, 1995). The $\mathrm{H}_{2} \mathrm{SO}_{4}$ (98\% by mass, $1.98 \mathrm{~g} \mathrm{~cm}^{-3}$ ) used in this process was of analytical grade. Lithium tetraborate $\left(\mathrm{LiB}_{4} \mathrm{O}_{7}\right)$ for digestion was supplied by Merck. Alkali-refined soybean oil was supplied by a vegetable oil plant located in Marsa, İstanbul. TOBE was procured from Süd Chemie (Germany).

\section{Acid activation}

Twenty-three samples, each with a mass of $20 \mathrm{~g}$, were weighed from the dried $\mathrm{CaB}$ powder and activated with $\mathrm{H}_{2} \mathrm{SO}_{4}$ using the dry method. The homogeneous muds prepared with the specific amounts of $\mathrm{CaB}, \mathrm{H}_{2} \mathrm{SO}_{4}$ and distilled water were heated at various temperatures. The mass fraction of $\mathrm{H}_{2} \mathrm{SO}_{4}(x)$ in the dry $\mathrm{CaB}$ and pure $\mathrm{H}_{2} \mathrm{SO}_{4}$ mixture of the first eight muds varied between 0 and 0.70. The amounts of water and $\mathrm{H}_{2} \mathrm{SO}_{4}$ in the $30 \mathrm{~mL}$ solution used for the preparation of the muds were calculated and are given in Table 1. Each mixture was heated at $100^{\circ} \mathrm{C}$ for $2 \mathrm{~h}$. Based on the first measurements, the highest $\mathrm{BP}$ was observed at the 0.35 mass fraction of $\mathrm{H}_{2} \mathrm{SO}_{4}$. Therefore, the mass fraction of $\mathrm{H}_{2} \mathrm{SO}_{4}$ in all time and temperature series experiments was set to 0.35 . Next, for the temperature series experiments, a set of seven muds with $x=0.35$ were heated for $2 \mathrm{~h}$ at temperatures ranging from $25^{\circ} \mathrm{C}$ to $250^{\circ} \mathrm{C}$. An activation time of $2 \mathrm{~h}$ was selected based on the optimum BP attained at various total structural metal oxides. Finally, for the time series experiments, the last seven muds having $x=0.35$ were heated at $100^{\circ} \mathrm{C}$, with time increasing from 0 to $20 \mathrm{~h}$. After activation, each sample was suspended in water and the solid residue was separated by centrifugation. Each residue was washed repeatedly with distilled water until the wash water was free of $\mathrm{SO}_{4}^{2-}$ against $\mathrm{BaCl}_{2}$ solution. The BEs obtained were dried at $105^{\circ} \mathrm{C}$ for $4 \mathrm{~h}$, ground so that they would pass through a $0.074 \mathrm{~mm}$ (200 mesh) sieve and kept 


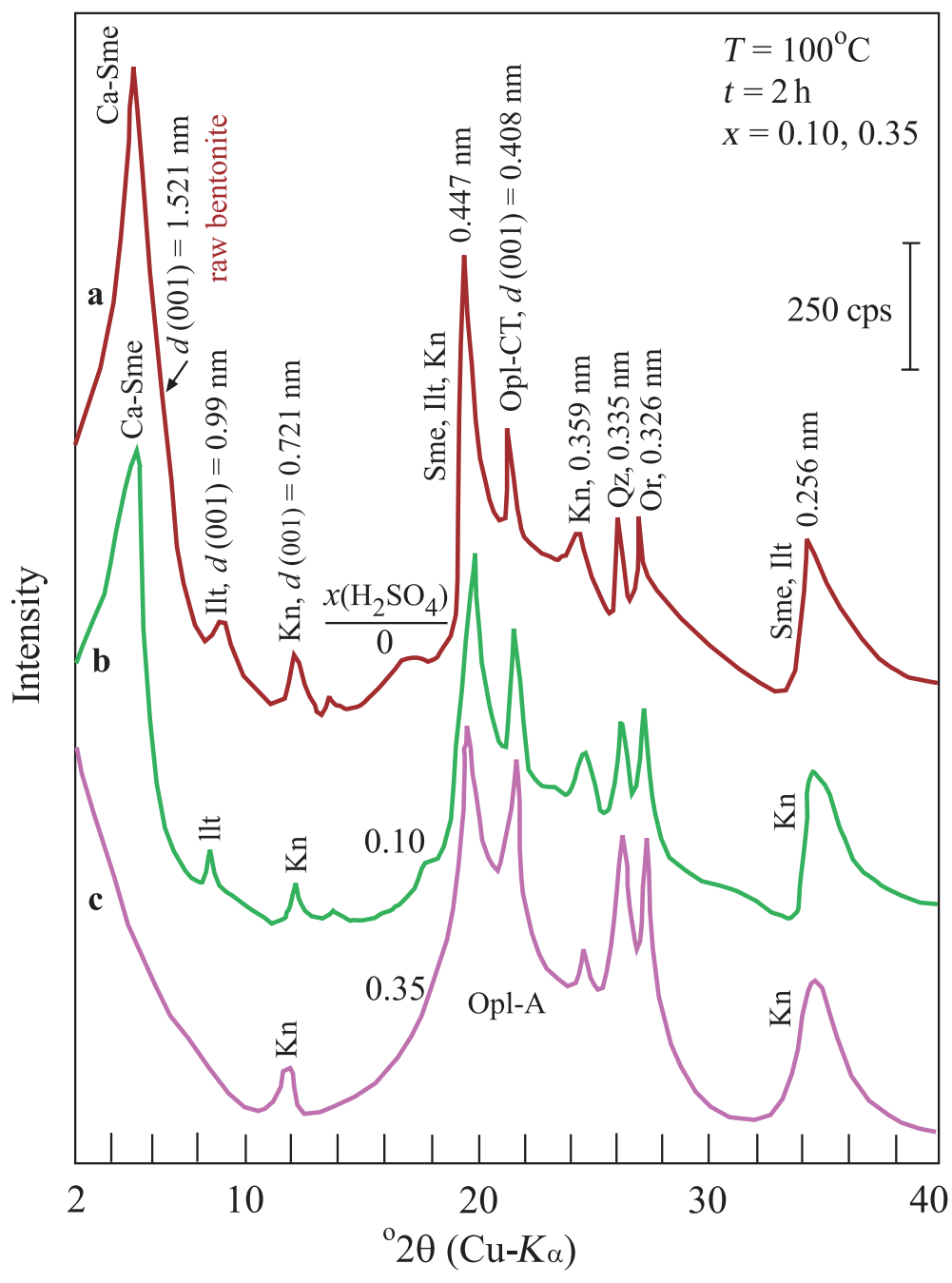

Fig. 1. XRD traces of (a) raw bentonite and (b, c) two representative activated samples.

in tightly closed plastic bottles. A total of 23 different BEs were prepared.

\section{Analytical procedures}

The $\mathrm{pH}$ value for each aqueous suspension having a BE content of $2 \%$ by mass was measured using an Orion Star A211 pH-Meter. The X-ray diffraction (XRD) traces for the raw $\mathrm{CaB}$ and acidactivated samples were recorded from mounts prepared using the glass slide method and run through a Rikagu D-max 2200 Diffractometer with a $\mathrm{Ni}$ filter and $\mathrm{Cu}-\mathrm{K \alpha}$ radiation with a wavelength of $0.15418 \mathrm{~nm}$ (Moore \& Reynolds, 1997). For chemical analyses, $\sim 0.25 \mathrm{~g}$ of dried sample was weighed into a platinum crucible, mixed with $3 \mathrm{~g} \mathrm{LiB}_{4} \mathrm{O}_{7}$, fused at $1000^{\circ} \mathrm{C}$ for $1 \mathrm{~h}$ and cooled to room temperature. Then, the crucible was placed in a beaker containing $1000 \mathrm{~mL}$ of $10 \% \mathrm{HCl}$ and heated to $90^{\circ} \mathrm{C}$ under stirring to dissolve the fused clays. The mass fractions of undissolved $\mathrm{Al}_{2} \mathrm{O}_{3}, \mathrm{Fe}_{2} \mathrm{O}_{3}$ and $\mathrm{MgO}$ in the $\mathrm{CaB}$ after the activation of the first nine samples were determined using atomic absorption spectrophotometry (AAS) with a Hitachi Z-8200 device. The results were given as the mass $\%$ of the metal oxides. The $\mathrm{N}_{2}$ adsorption/desorption data at $77 \mathrm{~K}$ for all of the activated samples were obtained at high vacuum using a volumetric adsorption instrument with a Pyrex glass connection
(Noyan et al., 2007). Before measurement, each sample was outgassed at $150^{\circ} \mathrm{C}$ for $4 \mathrm{~h}$ under vacuum $\left(10^{-3} \mathrm{mmHg}\right)$. The $S$ and $V$ values of the raw and acid-activated samples were calculated from the adsorption and desorption data, respectively (Rouquerol et al., 2014). The $D$ parameter of the mesopores assumed to be cylindrical was calculated from the following expression (Önal \& Sarıkaya, 2012; Rouquerol et al., 2014):

$$
D=4 V / S
$$

Bleaching experiments were carried out in an open $400 \mathrm{~mL}$ flask containing $2 \%$ by mass $\mathrm{BE}$ suspension in alkali-refined soybean oil. Each suspension was heated at $105^{\circ} \mathrm{C}$ for $15 \mathrm{~min}$ using the activated samples (Noyan et al., 2007). The oil was then filtered through Whatman No. 41 filter paper. The colour index of the oil in red-yellow units was determined using a Lovibond Automatic Tintometer (Type D) equipped with a $2.54 \mathrm{~cm}$ cell according to the American Oil Chemists' Society (AOCS) Official Method (Taylor et al., 1989). The BP value for each sample was calculated from the expression

$$
\mathrm{BP}=\left(R_{0}-R\right) / R_{0}
$$

where $R_{0}$ and $R$ are the red colour units on Lovibond scale of the alkali-refined oil prior to and after bleaching, respectively. 


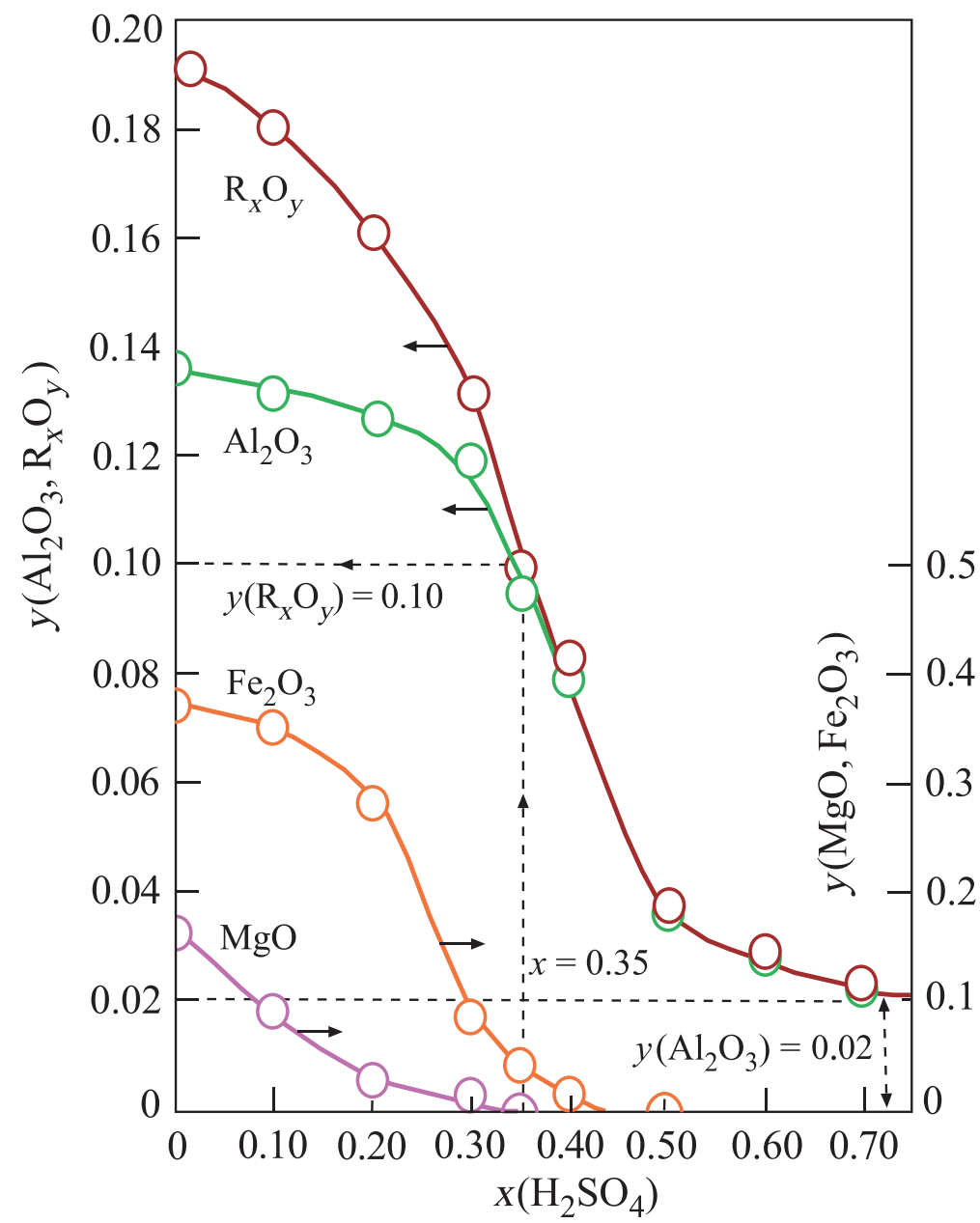

Fig. 2. Change in the mass fraction $(y)$ of the structural metal oxides $\left(\mathrm{Al}_{2} \mathrm{O}_{3}, \mathrm{Fe}_{2} \mathrm{O}_{3}, \mathrm{MgO}\right)$ and their totals $\left(\mathrm{R}_{x} \mathrm{O}_{y}\right)$ retained in the $\mathrm{Ca}$-Sme depending on the mass fraction $(x)$ of $\mathrm{H}_{2} \mathrm{SO}_{4}$, based on the dried $\mathrm{CaB}$ and pure acid mixtures.

\section{Results and discussion}

The XRD traces (Fig. 1a) revealed that the raw bentonite contained Ca-Sme, illite (Ilt), a kaolin group mineral (Kn), orthoclase (Or), quartz (Qz), opal-CT (Opl-CT) and probably some opal-A (Opl-A). The abbreviation symbols are after Warr (2020). As the major clay mineral was $\mathrm{Ca}-\mathrm{Sme}$, the raw material is $\mathrm{CaB}$. Ilt and $\mathrm{Kn}$ are the minor clay minerals, whereas Or, Qz, Opl-CT and Opl-A are non-clay impurities. The basal spacing $\left(d_{001}\right)$ values for the Ca-Sme, Ilt and $\mathrm{Kn}$ are 1.52, 1.00 and $0.72 \mathrm{~nm}$, respectively. The XRD traces (Fig. 1) showed that the Ca-Sme and Ilt particles decomposed completely through acid activation at $x=0.35$, but $\mathrm{Kn}, \mathrm{Or}, \mathrm{Qz}, \mathrm{Opl}-\mathrm{CT}$ and Opl-A were still observed.

The structural cations $\mathrm{Al}^{3+}, \mathrm{Fe}^{3+}$ and $\mathrm{Mg}^{2+}$ of $\mathrm{Ca}-\mathrm{Sme}$ and Ilt dissolved during the $\mathrm{H}_{2} \mathrm{SO}_{4}$ activation. The mass fraction $(y)$ of the corresponding metal oxides $\mathrm{Al}_{2} \mathrm{O}_{3}, \mathrm{Fe}_{2} \mathrm{O}_{3}$ and $\mathrm{MgO}$ and their sum, $\mathrm{R}_{x} \mathrm{O}_{y}$, decreased curvilinearly with increasing $x$ in the prepared muds (Fig. 2). Dissolution ceased at $x=0.70$. The remaining $\mathrm{Al}_{2} \mathrm{O}_{3}$ was probably present in undissolved $\mathrm{Kn}$ and Or impurities. These results are in agreement with Falaras et al. (1999), who also observed a decrease in the octahedral oxides $\left(\mathrm{Al}_{2} \mathrm{O}_{3}, \mathrm{MgO}\right.$, $\mathrm{Fe}_{2} \mathrm{O}_{3}$ ) due to dissolution of cations, including $\mathrm{Al}^{3+} \mathrm{Mg}^{2+}$ and $\mathrm{Fe}^{2+}$, during the acid activation of Ca-montmorillonite in the bleaching of cottonseed oil. Furthermore, Falaras et al. (1999) observed an increase in the specific surface area and acidity with decreasing $\mathrm{pH}$ (3.05) during acid activation, which is in agreement with the present study, suggesting a correlation between specific surface area, acidity and $\mathrm{pH}$. In a similar work, Mache et al. (2015) showed that $\mathrm{Al}, \mathrm{Mg}$ and $\mathrm{Fe}$ were leached from the octahedral and tetrahedral sheets of Ca-Sme, while the $\mathrm{SiO}_{4}$ groups of the tetrahedral sheets remained intact. Partial leaching of octahedral cations was correlated with the decrease in the $\mathrm{MgO}, \mathrm{Fe}_{2} \mathrm{O}_{3}$ and $\mathrm{Al}_{2} \mathrm{O}_{3}$ contents during the acid activation of smectitic clays. Finally, Saneei et al. (2015) focused on the optimization of acid activation parameters during the bleaching of sepiolite and observed a similar decrease in structural cations and reduction in $\mathrm{pH}$.

Changes in the $V, S, \mathrm{pH}$ and $\mathrm{BP}$ parameters were dependent on the $x$ and $y$ variables defined above (Fig. 3). The broad maxima of $V$ and $S$ are in the ranges $0.20<x<0.60$ and $0.04<y<0.16$. By contrast, the $\mathrm{pH}$ and $\mathrm{BP}$ values show a sharp minimum and a sharp maximum, respectively, for the same intervals. Their extreme values are $\mathrm{pH}=3.0$ and $\mathrm{BP}=0.60$ at $x=0.35$ and $y=0.10$ values. In addition, TOBE has an identical BP with the optimum BE that is used in the present study. Therefore, the acid-activation conditions for preparing the most suitable BEs are $x=0.35$, $T=100^{\circ} \mathrm{C}$ and $t=2 \mathrm{~h}$ (Fig. 3). Other investigated physicochemical properties of this sample were $y=0.10, V=0.31 \mathrm{~cm}^{3} \mathrm{~g}^{-1}$ and $S=225 \mathrm{~m}^{2} \mathrm{~g}^{-1}$. Consequently, the BP was observed to be more dependent on the $\mathrm{pH}$ (acidity) than the $V$ and $S$ values. Our results are in partial disagreement with the work of Falaras et al. (2000) in terms of the BP of TOBE because Falaras et al. demonstrated that 
Fig. 3. Variation in $V, S, B P$ and $\mathrm{pH}$ depending on the mass fractions of $x\left(\mathrm{H}_{2} \mathrm{SO}_{4}\right)$ and $y\left(\mathrm{R}_{x} \mathrm{O}_{y}\right)$.

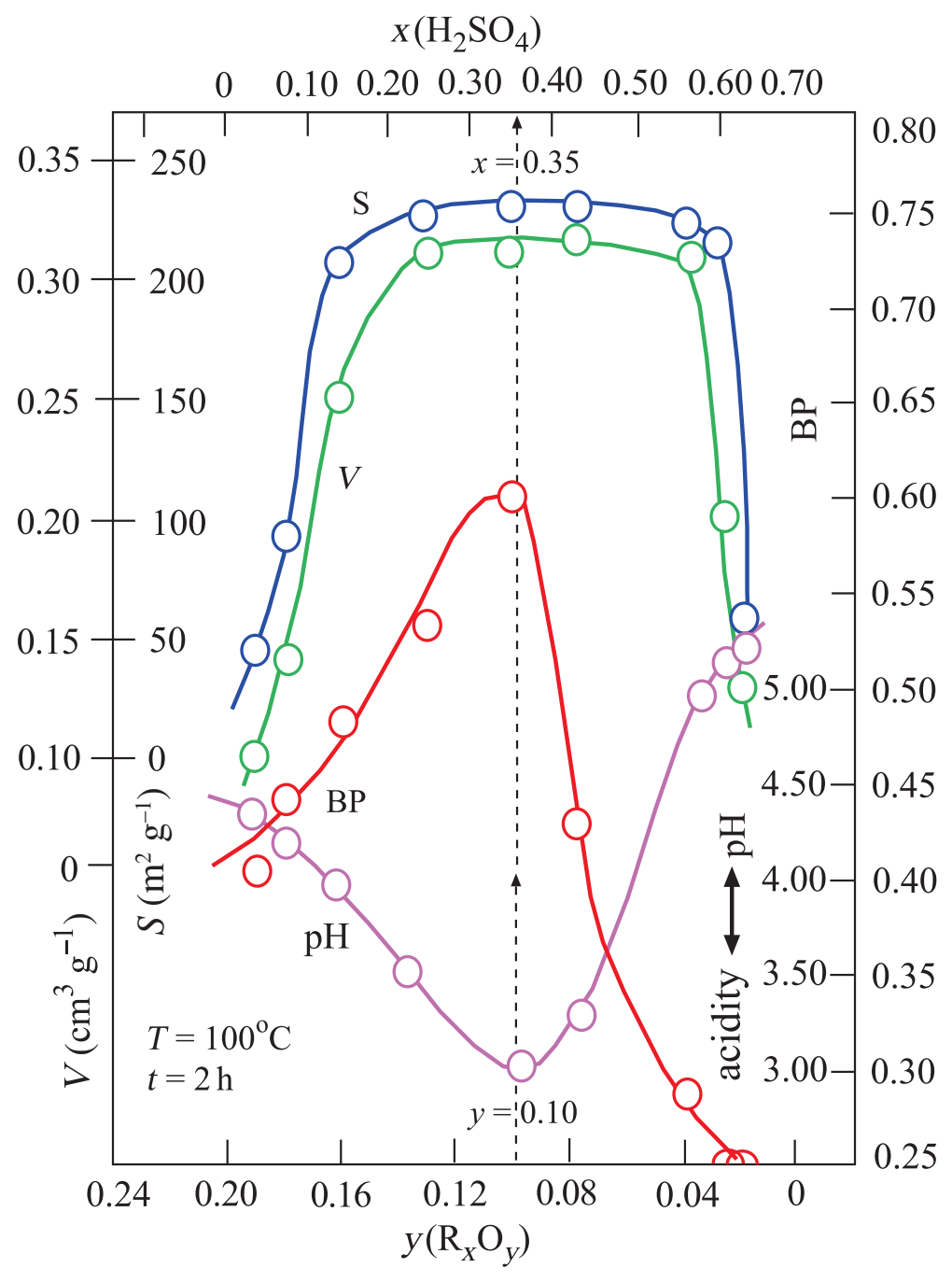

impactful on the bleaching of vegetable oils compared to the $V$ and $S$ values of the BE. Huang et al. (2007) investigated the impacts of pore-size distributions and specific surface areas of three attapulgite samples on the bleaching of soybean oil and suggested that the most effective pore size for the best BP is $0.8-3.2 \mathrm{~nm}$. The similarity of the pore size of attapulgite to the diameter of the pigments enhanced the BP by enabling the rapid removal of these pigments. Even though various BEs were used in this study and that of Huang et al. (2007), the conclusion of Huang et al. regarding the importance of compatibility between the $\mathrm{BE}$ and pigments on the $\mathrm{BP}$ is in accordance with the present work.

The adsorption of coloured pigments onto the BE depends not only on the physicochemical interactions between large organic molecules and the BE surface, but also on the acidity and mesopore size. The compatibility in size between the pigments and internal widths of the mesopores in the $\mathrm{BE}$ is the most important parameter that controls the BP.

\section{Conclusions}

Various BEs were produced using $\mathrm{H}_{2} \mathrm{SO}_{4}$ activation of a $\mathrm{CaB}$ under varying mass fractions of $\mathrm{H}_{2} \mathrm{SO}_{4}$, heating temperature 

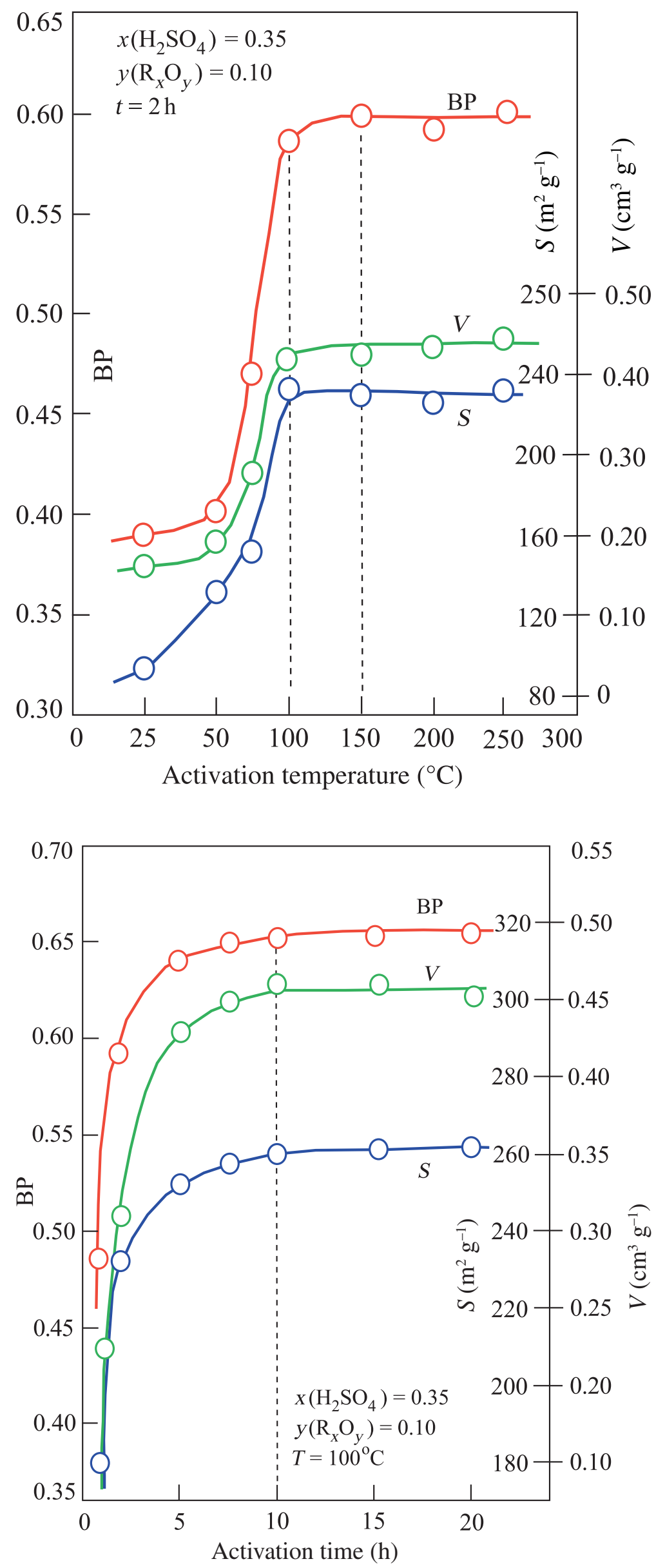

Fig. 4. Variation in $V, S$ and BP depending on the process temperature in experiments conducted for $2 \mathrm{~h}$ at the constant value of $x\left(\mathrm{H}_{2} \mathrm{SO}_{4}\right)=0.35$ and corresponding $y\left(\mathrm{R}_{x} \mathrm{O}_{y}\right)=0.10$.
Fig. 5. Variation in $V, S$ and $B P$ depending on the process time in experiments conducted at $100^{\circ} \mathrm{C}$ at the constant value of $x\left(\mathrm{H}_{2} \mathrm{SO}_{4}\right)=0.35$ and corresponding $y\left(\mathrm{R}_{x} \mathrm{O}_{y}\right)=0.10$. 


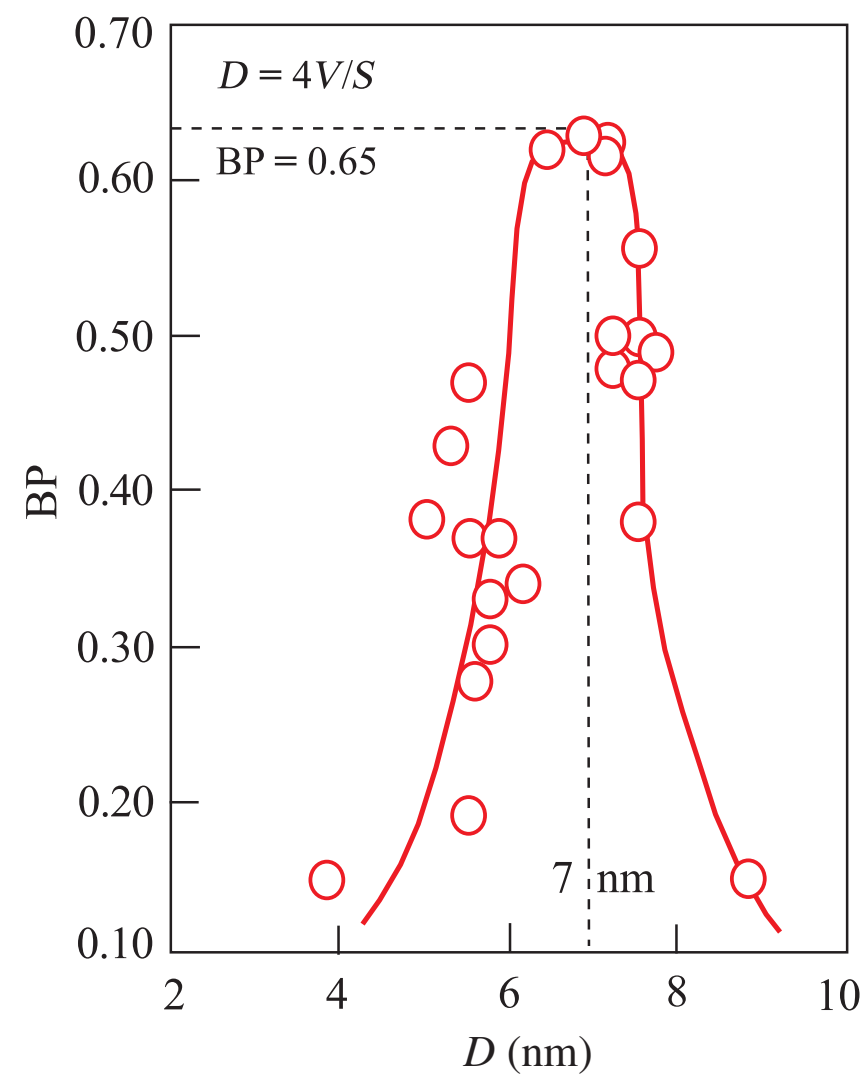

Fig. 6. Variation in BP with the mean internal width $(D)$ of the pores, which was calculated depending on the $V$ and $S$ values for all activated samples from the relationship of $D=4 V / S$ using SI units.

and contact time in an attempt to bleach an alkali-refined oil. The main conclusions are as follows:

(1) The 2:1 clay minerals such as montmorillonite and Ilt decomposed completely after treatment with an adequate amount of $\mathrm{H}_{2} \mathrm{SO}_{4}$. In contrast, the 1:1 kaolin group clay mineral Or as well as Qz, Opl-CT, and Opl-A were less affected by the activation.

(2) Activation results in a non-linear decrease in the $\mathrm{Al}_{2} \mathrm{O}_{3}$, $\mathrm{Fe}_{2} \mathrm{O}_{3}$ and $\mathrm{MgO}$ of the clays with increasing mass fraction of $\mathrm{H}_{2} \mathrm{SO}_{4}$. To fully constrain this relationship, the direction and the equilibrium state of the reaction between the octahedral ions and the amount of acid should be investigated in future studies.

(3) The micropore and mesopore volumes, specific surface area and $\mathrm{BP}$ of the BEs reach their maximum values when the mass percentage of $\mathrm{H}_{2} \mathrm{SO}_{4}$ and the mass percentage of undissolved metal oxide reach specific values. These maxima not only depend on the temperature of the activation, but also increase with increasing time when other variables are kept constant.

(4) The most effective internal width of the mesopores is $7 \mathrm{~nm}$.

(5) The optimum conditions for the production of the most effective $\mathrm{BE}$ for an alkali-refined vegetable oil depends on the type and ratio of the raw bentonite and $\mathrm{H}_{2} \mathrm{SO}_{4}$, as well as the temperature and duration of activation.

(6) To obtain more comprehensive results, the optimum parameters need to be determined individually for each raw bentonite and edible oil pair.
Acknowledgements. The authors thank the reviewers and S. Kaufhold for their detailed and constructive comments that improved the quality and clarity of the paper. The authors are also grateful to G. Christidis for the editorial handling of this manuscript.

Financial support. This research was supported by Ankara University Scientific Research Projects Coordination Unit (19L0430007).

\section{References}

Almeida E.S., Carvalho A.C.B., de Souza Soares I.D., Valadares L.F., Mendonça A.R.V., Silva I.J. Jr \& Monteiro S. (2019) Elucidating how to different types of bleaching earths widely used in vegetable oils industry remove carotenes from palm oil: equilibrium, kinetics and thermodynamics parameters. Food Research International, 121, 785-797.

Awad A.M., Shaikh S.M.R., Jalab R., Gulied M.H., Nasser M.S., Benamor A. \& Adham S. (2019) Adsorption of organic pollutants by natural and modified clays: a comprehensive review. Separation and Purification Technology, 228, 115719.

Bergaya F., Theng B.K.G. \& Lagaly G. (2006) Handbook of Clay Science. Elsevier, Amsterdam, The Netherlands, $1224 \mathrm{pp}$.

Bombos D., Ganea R., Matei V., Mawnescu C., Bodnarev A., Mihai S. et al. (2014) Modified bentonite for purification of dyeing waste water. Revista de Chimie, 65, 976-982.

Brimberg U.I. (1982) Kinetics of bleaching of vegetable oils. Journal of the American Oil Chemists' Society, 59, 74-78.

Christidis G.E., Scott P.W. \& Dunham A.C. (1997) Acid activation and bleaching capacity of bentonites from the island of Milos and Chios, Aegean, Greece. Applied Clay Science, 12, 329-347.

Emmerich K., Steudel A., Schuhmann R., Weidler P.G., Ruf F. \& Sohling U. (2010) Mineralogical and physicochemical characterization of a natural bleaching earth containing sepiolite suitable for fast filtration and bioseparation. Clay Minerals, 45, 477-488.

Falaras P., Kovanis I., Lezou F. \& Seiragakis G. (1999) Cottonseed oil bleaching by acid activated montmorillonite. Clay Minerals, 34, 221-232.

Falaras P., Lezou F., Seiragakis G. \& Petrakis D. (2000) Bleaching properties of alumina-pillared acid-activated montmorillonite. Clays and Clay Minerals, 48, 549-556.

Hang R.T. \& Brindley G.W. (1970) Methylene blue adsorption by clay minerals. Determination of surface areas and cation exchange capacities (clay-organic studies XVIII). Clays and Clay Minerals, 18, 203-312.

Hew K.S., Asis A.J., Tan T.B., Yusoff M.M., Lai O.M., Nehdi I.A. \& Tan C.P. (2020) Revising degumming and bleaching processes of palm oil refining for the mitigation of 3-monochloropropane-1,2-diol esters (3-MCPDE) and glycidyl esters (GE) contents in refined palm oil. Food Chemistry, $307,125545$.

Huang J., Liu Y., Liu Y. \& Wang X. (2007) Effect of attapulgite pore size distribution on soybean oil bleaching. Journal of the American Oil Chemists' Society, 84, 687-692.

Kahr G. \& Madson F.T. (1995) Determination of the cation exchange capacity and surface area of bentonite, illite, and kaolinite by methylene blue adsorption. Applied Clay Science, 9, 327-336.

Kipling J.J \& Wilson R.B. (1960) Adsorption of methylene blue in the determination of surface areas. Journal of Applied Chemistry, 10, 109-113.

Komadel P. (2003) Chemically modified smectites. Clay Minerals, 38, 127-138.

Komadel P. (2016) Acid activated clays: materials in continuous demand. Applied Clay Science, 131, 84-99.

Koutsopoulou E., Christidis G.E. \& Marantos I. (2016) Mineralogy, geochemistry and physical properties of bentonites from the Western Thrace Region and the islands of Samos and Chios, East Aegean, Greece. Clay Minerals, 51, 563-588.

Laatikainen M., Srithammavut W., Toukonitty B., Turunen I. \& Sainio T. (2015) Phospholipid adsorption from vegetable oils on acid on acidactivated sepiolite. Adsorption, 21, 409-417.

Liang X., Yang C., Su X. \& Xue X. (2020) Regeneration of spent bleaching clay by ultrasonic irradiation and its application in methylene blue adsorption. Clay Minerals, 55, 24-30. 
Mache J.R., Signing P., Mbey J.A., Razafitianamaharavo A., Njopwouo D. \& Fagel N. (2015) Mineralogical and physico-chemical characteristics of Cameroonian smectitic clays after treatment with weakly sulfuric acid. Clay Minerals, 50, 649-661.

Moore D.M. \& Reynolds R.C. Jr (1997) X-Ray Diffraction and the Identification and Analysis of Clay Minerals (2nd ed.). Oxford University Press, Oxford, UK, 400 pp.

Mounts T.L. (1981) Chemical and physical effects of processing fats and oils. Journal of the American Oil Chemists' Society, 58, 51A-54A.

Noyan H., Önal M. \& Sarkaya Y. (2007) The effect of sulphuric acid activation on the crystallinity, surface area, porosity, surface acidity, and bleaching power of a bentonite. Food Chemistry, 105, 156-163.

Omar S., Girgis B. \& Taha F. (2003) Carbonaceous materials from seed hulls for bleaching of vegetable oils. Food Research International, 36, 11-17.

Önal M. \& Sarıkaya Y. (2007) Preparation and characterization of acidactivated bentonite powders. Powder Technology, 172, 14-18.

Önal M. \& Sarıkaya Y. (2012) Maximum bleaching of vegetable oils by acidactivated bentonite: influence of nanopore radius. Adsorption Science and Technology, 30, 97-104.

Özgüven F.E., Pekdemir A.D., Önal M. \& Sarıkaya Y. (2020) Characterization of a bentonite and its permanent aqueous suspension. Journal of the Turkish Chemical Society A: Chemistry, 7, 11-18.

Pentrák M., Madejová J. \& Komadel P. (2009) Acid and alkali treatment of kaolins. Clay Minerals, 44, 511-523.

Rich A.D. (1964) Some basic factors in the bleaching of fatty oils. Journal of the American Oil Chemists' Society, 41, 315-321.

Rouquerol F., Rouquerol J., Sing K.S.W., Llewellyn P.I. \& Maurin G. (2014). Adsorption by Powders and Porous Solids. Elsevier, Amsterdam, The Netherlands, $467 \mathrm{pp}$.

Rytwo G., Serban C., Nir S. \& Margulies L. (1991) Use of methylene blue and crystal violet for determination of exchangeable cations in montmorillonite. Clays and Clay Minerals, 39, 551-555.

Saneei M., Goli S.A.H. \& Keramat J. (2015) Optimization of oil bleaching parameters, using response surface methodology, for acid-activated sepiolite from Iran. Clay Minerals, 50, 639-648.
Silva S.M., Sampaio K.A., Ceriani R., Verhé R., Stevens C., Greyt W.D. \& Meirelles A.J.A. (2014) Effect of type of bleaching earth on the final color of refined palm oil. LWT - Food Science and Technology, 59, 1258-1264.

Sohling U., Ruf F., Schurz K., Emmerich K., Steudel A., Schuhmann R. et al. (2009) Natural mixture of silica and smectite as a new clayey material for industrial applications. Clay Minerals, 44, 525-537.

Steudel A., Mehl D. \& Emmerich K. (2013) Simultaneous thermal analysis of different bentonite-sodium carbonate systems: an attempt to distinguish alkali-activated bentonites from raw materials. Clay Minerals, 48, $117-128$.

Taxiarchou M. \& Douni I. (2014) The effect of oxalic acid activation on the bleaching properties of a bentonite from Milos Island, Greece. Clay Minerals, 49, 541-549.

Taylor D.R., Jenkins D.B. \& Ungermann C.B. (1989) Bleaching with alternative layered minerals: a comparison with acid-activated montmorillonite for bleaching soybean oil. Journal of the American Oil Chemists Society, 66, 334-341.

Tian G., Wang W., Kang Y. \& Wang A. (2014) Study on thermal activated sepiolite for enhancing decoloration of crude palm oil. Journal of Thermal Analysis and Calorimetry, 117, 1211-1219.

Uddin M.K. (2017) A review on the adsorption of heavy metals by clay minerals, with special focus on the past decade. Chemical Engineering Journal, 308, 438-462.

Warr L.N. (2020) Recommended abbreviations for the names of clay minerals and associated phases. Clay Minerals, 55, 261-264.

Zhu R., Chen Q., Zhou Q., Xi Y., Zhu J. \& He H. (2016) Adsorbents based on montmorillonite for contaminant removal water: a review. Applied Clay Science, 123, 239-258.

Zschau W. (1985) Was ist Bleicherde? Fette Seifen Anstrichmittel, 87, 506-508.

Zschau W. (1999) Die Bleichung von Speisefetten und Ölen VII. Qualitätskontrolle der Bleichung. Aus dem Arbeitskreis 'Technologien der industriellen Gewinnung und Verarbeitung von Speisefetten'. Lipid/Fett: European Journal of Lipid Science and Technology, 101, 117-119. 